\title{
A Correlational Analysis of Length and Nature of Relationships Between Applicant and Reference and Strength of Recommendation for CASPA Letters of Recommendation
}

Ty Troxell

Central Michigan University, ttroxell13@gmail.com

John E. Lopes Jr

Central Michigan University, lopes1je@cmich.edu

Follow this and additional works at: https://nsuworks.nova.edu/ijahsp

Part of the Medical Education Commons

\section{Recommended Citation}

Troxell T, Lopes JE. A Correlational Analysis of Length and Nature of Relationships Between Applicant and Reference and Strength of Recommendation for CASPA Letters of Recommendation. The Internet Journal of Allied Health Sciences and Practice. 2019 Jan 01;17(2), Article 7.

This Manuscript is brought to you for free and open access by the College of Health Care Sciences at NSUWorks. It has been accepted for inclusion in Internet Journal of Allied Health Sciences and Practice by an authorized editor of NSUWorks. For more information, please contact nsuworks@nova.edu. 


\title{
A Correlational Analysis of Length and Nature of Relationships Between Applicant and Reference and Strength of Recommendation for CASPA Letters of Recommendation
}

\begin{abstract}
Background: The Central Application Service for Physician Assistants (CASPA) application includes a standardized rating form in addition to the ability to submit letters of recommendation. This exploratory study examines the standardized portion of the CASPA letter of recommendation to determine whether there is a correlation between the ratings given and the relationship and length of time the writer knew the applicant. Method: Four-hundred and thirty recommendation forms were evaluated. Variables included length and nature of the relationship between the letter writer and the overall recommendation given by the writer for the applicant. Results: Almost $95 \%$ of writers highly recommended the applicant. There was a weak correlation between length of relationship and overall evaluation rating and recommendation to the program $r=0.12$ and $r=0.17$, respectively. A moderate correlation was found between the nature of the relationship $(r=0.34)$ and overall evaluation $(r=0.30)$. Conclusion: This study might indicate that the nature of the relationship between the writer and applicant and may provide programs with a metric to evaluate the strength of letters of recommendation.
\end{abstract}

\section{Author Bio(s)}

Ty Troxell, BS is a 2018 graduate of Central Michigan University. This article is the result of research performed for his Honors Program Capstone project.

John E. Lopes Jr., DHSc, PA-C is an Associate Professor in the Physician Assistant program at Central Michigan University. He served as Mr Toxell's Honors project advisor. 


\title{
1IVAHSP \\ The Internet Joumnal of Allied Health Sciences and Practice \\ Dedicated to allied health professional practice and education \\ Vol. 17 No. 2 ISSN 1540-580X
}

\section{A Correlational Analysis of Length and Nature of Relationships Between Applicant and Reference and Strength of Recommendation for CASPA Letters of Recommendation}

\author{
Ty Troxell \\ John E. Lopes Jr. \\ Central Michigan University \\ United States
}

\begin{abstract}
Background: The Central Application Service for Physician Assistants (CASPA) application includes a standardized rating form in addition to the ability to submit letters of recommendation. This exploratory study examines the standardized portion of the CASPA letter of recommendation to determine whether there is a correlation between the ratings given and the relationship and length of time the writer knew the applicant. Method: Four-hundred and thirty recommendation forms were evaluated. Variables included length and nature of the relationship between the letter writer and the overall recommendation given by the writer for the applicant. Results: Almost $95 \%$ of writers highly recommended the applicant. There was a weak correlation between length of relationship and overall evaluation rating and recommendation to the program $r=0.12$ and $r=0.17$, respectively. A moderate correlation was found between the nature of the relationship $(r=0.34)$ and overall evaluation $(r=0.30)$. Conclusion: This study might indicate that the nature of the relationship between the writer and applicant and may provide programs with a metric to evaluate the strength of letters of recommendation.
\end{abstract}

Keywords: CASPA, letter of reference, length of relationship, nature of relationship 


\section{INTRODUCTION}

Every year, students pursue graduate education. Most students do so by submitting a formal application to their program of choice in hopes of acceptance to the program upon review of the application. Most programs will require transcripts of coursework, completion of prerequisite courses, and letters of recommendation from people familiar with the student's academic and personal accomplishments. Many programs, Central Michigan University's Physician Assistant Program included, participate in the Centralized Application Service for Physician Assistants (CASPA), which allows students to submit their application to a number of schools at the same time. Participating programs access applicants' submissions through CASPA. CASPA provides a private website link to persons providing letters of reference with instructions on how to submit a written narrative letter and completing a qualitative assessment of the applicant. The recommendation form also collects information about the evaluator, such as their relationship with the applicant. Through CASPA, the applicant is given the option to waive their right to see the evaluation, and most are expected to do so. Central Michigan University's Physician Assistant Program requires applicants to submit three letters of recommendation. A variety of individuals complete these evaluation forms. Professors, advisors, employee/supervisors, coworkers, and shadowed healthcare professionals who know the applicant to some degree comprise the majority of these recommenders.

The letter of recommendation form that CASPA provides includes a standardized scoring section where applicants are assessed on a qualitative scale of "poor" to "excellent" for these characteristics: adaptability, conflict resolution, empathy, intellectual ability, interpersonal relations, oral communication, reaction to criticism, reliability, self-awareness, team skills, written communication, and an overall evaluation. In addition to these ratings, the evaluators complete questions regarding the length of their relationship with the applicant, how well they know the applicant, and their mode of interaction. The final area of response offers the evaluator the opportunity to select how highly they recommend the applicant.

The utility of letters of recommendation has been the subject of debate for many years. Some argue that they are biased and unreliable; however, many agree that they are a necessary component of any application. Current literature is lacking regarding the use of letters of recommendation in Physician Assistant Programs.

Fiona Patterson and her colleagues examined the effectiveness of letters of recommendation for selection methods in medical education by conducting a systematic review of the literature. They concluded that the narrative letters did not predict the applicant's performance in medical school consistently. ${ }^{1}$ Patterson's research also identified that it may not be cost effective for admissions committees to evaluate the references. For committees to interpret these letters and score them, valuable time and resources would be wasted. There appears to be a consensus that these narrative letters of recommendation are unreliable and invalid in terms of selected students for medical school. ${ }^{1}$ Issues like these led to the rise of the standardized letters of recommendation, similar to the CASPA form. In addition, one study examining the perception of surgical residency program directors in Canada found that only about half of the 65 participating directors believed letters of recommendation could help predict an applicant's success in their program. ${ }^{2}$ These directors believed that mention of work ethic, interpersonal skills, and teamwork were important parts of letters of evaluation. Notably, these qualities are more easily rated in a standardized format. The same study found that about half of the directors also believed their familiarity with the applicant's evaluator influenced the letter's reliability in their eyes. ${ }^{2}$ In medical education, it appears that letters of recommendation could have potential downfalls, especially the narrative letter.

In contrast to medical education, there have been studies on narrative letters of recommendation in other fields of study as well. One study on postdoctoral fellowships in the geosciences found that letters of recommendation showed a gender bias in the field. ${ }^{3}$ This study, conducted by Dutt and colleagues, examined the relationship between an applicant's gender and the letter's tone and length. The study concluded that female applicants were half as likely as male applicants to receive stellar letters. ${ }^{3}$ Another study, involving high school student counselors, found that there was a bias in letters related to the gender of the evaluators. ${ }^{4}$ The study found that letters written by female recommenders were statistically longer than those written by males. Messner and Shimahara evaluated letters of recommendation for applicants to ENT residencies. ${ }^{5}$ A significant finding was that letters written by women were more likely to refer to the applicant's team skills and compassion and use strings of adjectives describing the applicant.

Narrative letters are often supplemented by an additional standardized evaluation form, like the one used in the CASPA application. The Family Education Rights and Privacy Act, enacted in 1974, provides applicants the right to see letters written about them in academic contexts. ${ }^{6}$ However, the Buckley Amendment, a later addition, allows students to waive their right of access in admission cases. Ceci and Peters found that when letters were confidential, and applicants could not see the ratings assigned to them on a standardized form, the evaluators were more likely to rate the applicant lower. ${ }^{6}$ The reverse was also seen; if the letters were viewed by the applicants, the recommender's evaluation scores were higher. Narrative letters may also serve an advocacy function for applicants as opposed to a true evaluation of their competence. ${ }^{7}$ 
Proponents of the standardized letter of recommendation cite multiple reasons for the shift away from its narrative counterpart. Those in favor suggest that standardized forms are easier and more time-efficient for both the writers and the admissions staff. ${ }^{8}$ The standardized forms of evaluation do not require the admissions staff to have the same training as the narrative letters do, and in terms of medical education appear to offer a more specialty-specific evaluation to programs. The quantitative data produced from these forms appear to be more discriminatory than the qualitative written letters. However, Kominsky and colleagues found that the variability of ratings on standardized forms is low. ${ }^{9}$ The form used by the Electronic Residency Application Service has ten questions where the evaluator must rank the applicant on a scale from Top to Bottom in regard to the applicant's suitability for the residency. Kominsky and colleagues report that only one of the ten categories produced a mean response below the $85^{\text {th }}$ percentile for the number line. In addition, the study found that all scores increased as the length of relationship increased, which suggests a familiarity bias. ${ }^{9}$ There is also a suggestion that most individuals who write these letters have a natural inclination to avoid causing damage to the applicant's chances.

Central Michigan University's (CMU) Physician Assistant (PA) program, like many others, seeks to apply an objective review process for prospective students. Prior research has clearly shown that letters of recommendation can be affected by varying instances of bias, and the standardized forms are not necessarily effective to discriminate between applicants. This exploratory study will examine the following questions: 1)Does the length of time that a writer has known the applicant have any correlation to the ratings given? and 2) Is there a correlation between the nature of the relationship between the writer and the applicant and the ratings given? It is expected that this information will provide a discussion point for PA program admission committees when determining what emphasis to place on the letters of recommendation of their applicants.

\section{METHODS}

This study was determined to be "Not human subject research" by the CMU Institutional Review Board. The study was conducted as the Capstone project for the CMU Honors Program. Letters of recommendation from the 120 applicants selected for an interview at the CMU PA program were printed from the CASPA file and de-identified. There are pre-determined responses to each question about the nature of the relationship between the writer and the applicant. The form asks the evaluators to rate the applicant in the categories of adaptability, conflict resolution, empathy, intellectual ability, interpersonal relations, oral communication, reaction to criticism, reliability, self-awareness, team skills, and written communication. Finally, they were given an overall evaluation on the same scale from "poor" to "excellent." Each of the responses was coded to allow entry into an Excel spreadsheet and statistical analysis. Frequencies of the responses and ratings were calculated. Correlations between the length of the relationship and how well the evaluator knew the applicant to the overall evaluation rating and the level of recommendation were then determined.

\section{RESULTS}

Four hundred and thirty letters were analyzed from the 120 applicants granted an interview. Table 1 indicates that about two-thirds of letter writers knew the applicant for three years or less.

Table 1. How long have you known the applicant?

\begin{tabular}{ll}
\hline Length of Relationship & $\begin{array}{l}\text { Frequency of } \\
\text { Response (\%) }\end{array}$ \\
\hline$<1$ year & $72(16.7)$ \\
1-2 years & $129(30)$ \\
2-3 years & $80(18.6)$ \\
3-5 years & $74(17.3)$ \\
5-10 years & $37(8.6)$ \\
$>10$ years & $38(8.8)$ \\
\hline Total & 430 \\
\hline
\end{tabular}

Writers were almost equally split between those who knew the applicant very well (52\%) and those who knew the applicant moderately or minimally well (47\%; Table 2$)$ 
Table 2. How well do you know the applicant?

\begin{tabular}{ll}
\hline Familiarity with Applicant & $\begin{array}{l}\text { Frequency of Responses } \\
(\%)\end{array}$ \\
\hline Minimally & $20(4.7)$ \\
Moderately & $182(42.3)$ \\
Very Well & $228(53)$ \\
\hline Total & 430 \\
\hline
\end{tabular}

Table 3 shows that almost two-thirds of applicants asked instructors (30\%) and supervisors $(30.9 \%)$ to write their letters of recommendation.

Table 3. Relationship to applicant

\begin{tabular}{ll}
\hline Relationship to the applicant & $\begin{array}{l}\text { Frequency of } \\
\text { Responses (\%) }\end{array}$ \\
\hline Other & $35(8.1)$ \\
Colleague/Coworker & $51(11.8)$ \\
Employee/Supervisor & $133(30.9)$ \\
Internship/Job Shadowing & $69(16)$ \\
Instructor/Professor & $129(30)$ \\
Advisor & $13(3)$ \\
\hline Total & $\mathbf{4 3 0}$ \\
\hline
\end{tabular}

The final prompt on the standardized evaluation form is the evaluator's overall recommendation to the program regarding the applicant's admission. Twenty-one (4.9\%) indicated a "recommend", while 407 (94.9\%) responders highly recommended the applicant. One writer did not complete this section. Only one of $429(0.2 \%)$ writers did not recommend the program admit the applicant.

Table 4. Recommendation concerning admission

\begin{tabular}{ll}
\hline $\begin{array}{l}\text { Recommendation to } \\
\text { Program }\end{array}$ & $\begin{array}{l}\text { Frequency of Responses } \\
\text { (\%) }\end{array}$ \\
\hline Do Not Recommend & $1(0.2)$ \\
Recommend & $21(4.9)$ \\
Highly Recommend & $407(94.9)$ \\
\hline Total & $\mathbf{4 2 9 *}$ \\
\hline *One writer did not indicate a recommendation \\
\hline
\end{tabular}

Tables $5 \mathrm{a}$ and $5 \mathrm{~b}$ represent the responses rating certain attributes of the applicant. Between $85 \%$ and $100 \%$ of writers indicated that the applicants exhibited Excellent or Good levels of these attributes. Writers did not indicate a rating for some of the attributes with Conflict Resolution (14.6\%) and Written Communication (11.8\%) most often not rated. Of the 430 forms, only one writer 
selected a "poor" rating for written communication. All of the overall ratings across the 11 attributes were Good (7.9\%) or Excellent $(92.1 \%)$.

Table 5a. Attributes

\begin{tabular}{|c|c|c|c|c|c|c|}
\hline 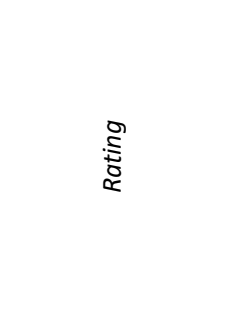 & 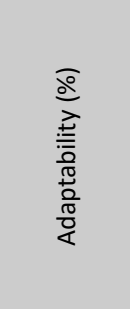 & 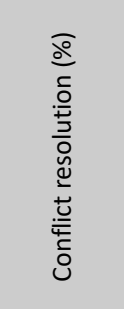 & 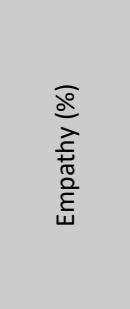 & 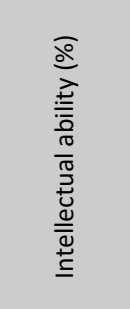 & 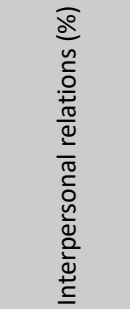 & 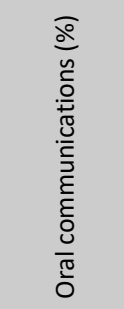 \\
\hline$O(N / A)$ & $7(0.02)$ & $63(14.6)$ & $16(3.7)$ & $1(0.02)$ & $3(0.06)$ & $3(0.06)$ \\
\hline 1 (Poor) & 0 & 0 & 0 & 0 & 0 & 0 \\
\hline 2 (Below average) & 0 & 0 & 0 & 0 & 0 & 0 \\
\hline 3 (Average) & 0 & $4(0.09)$ & $1(0.02)$ & $2(0.04)$ & $1(0.02)$ & $3(0.06)$ \\
\hline 4 (Good) & $57(13.2)$ & $87(20.2)$ & 49 (11.4) & $48(11.2)$ & 51 (11.8) & 76 (17.6) \\
\hline 5 (Excellent) & $366(85.1)$ & 276 (64.1) & 364 (84.6) & $379(88.1)$ & $375(87.2)$ & 348 (80.9) \\
\hline Total & 430 & 430 & 430 & 430 & 430 & 430 \\
\hline
\end{tabular}

Table 5b. Attributes

\begin{tabular}{|c|c|c|c|c|c|c|}
\hline 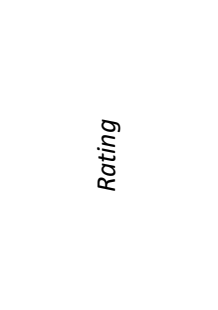 & 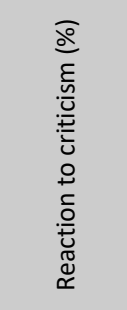 & 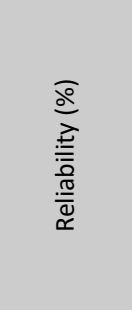 & 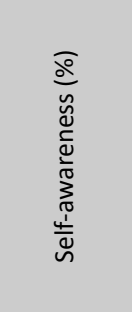 & 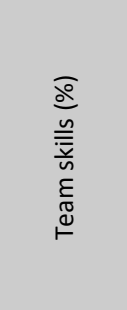 & 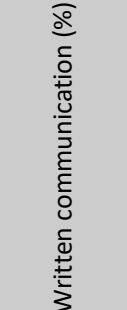 & 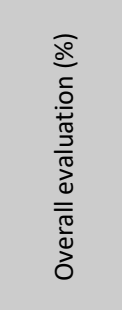 \\
\hline$O(N / A)$ & $12(2.7)$ & $1(0.02)$ & $15(3.4)$ & $22(5.1)$ & $51(11.8)$ & 0 \\
\hline 1 (Poor) & 0 & 0 & 0 & 0 & $1(0.02)$ & 0 \\
\hline 2 (Below average) & 0 & 0 & 0 & 0 & 0 & 0 \\
\hline 3 (Average) & $6(1.3)$ & 0 & $6(1.3)$ & $2(0.04)$ & $5(1.1)$ & 0 \\
\hline 4 (Good) & 79 (18.3) & $24(5.6)$ & $66(15.3)$ & $39(9.0)$ & $74(17.2)$ & 34 (7.9) \\
\hline 5 (Excellent) & $303(70.4)$ & 405 (94.2) & 343 (79.7) & $367(85.3)$ & 299 (69.5) & 396 (92.1) \\
\hline Total & 430 & 430 & 430 & 430 & 430 & 430 \\
\hline
\end{tabular}

Correlational analysis indicates a weak correlation between length of relationship and overall evaluation rating $(r=0.12)$ and recommendation to the program ( $\mathrm{r}=0.17$ ) (Table 6$)$. A moderate correlation is seen between nature of the relationship and overall evaluation $(r=0.34)$ and recommendation to the program $(r=0.30)$. 
Table 6. Correlation between overall evaluation and recommendation to the program and length of relationship and nature of the relationship.

\begin{tabular}{lll}
\hline Variable & $\begin{array}{l}\text { Correlation with } \\
\text { Overall Evaluation } \\
\text { Rating }\end{array}$ & $\begin{array}{l}\text { Correlation with } \\
\text { Recommendation to } \\
\text { the Program }\end{array}$ \\
\hline & & \\
\hline $\begin{array}{l}\text { Length of } \\
\text { Relationship } \\
\text { Nature of } \\
\text { Relationship }\end{array}$ & 0.1263 & 0.173 \\
\hline
\end{tabular}

\section{DISCUSSION}

Writers of letters of recommendation uniformly rate applicants at the top of the rating scales with little to no correlation to how long they have known the applicant or in what context the relationship existed. Kominsky and colleagues found that such small variability in ratings is unlikely to provide a metric for discriminating between applicants, a finding also identified by this analysis. ${ }^{9}$ This analysis might indicate that the nature of the relationship between the applicant and letter writer may provide programs with a metric to evaluate the strength of letters of recommendation.

Despite the trend towards unreliability, standardized letters of recommendation may still serve a purpose to admissions departments. They are able provide a "red flag" if the ratings are low, or if the evaluator does not recommend the applicant to the program. If an applicant has ratings, or an overall recommendation at the lowest level, the reviewer of the application will easily be able to notice the difference and discern between applicants. Further avenues for research include whether the ratings provided on standardized letters of recommendation are able to accurately predict an applicant's ability to succeed in the physician assistant program and whether the ratings on the standardized portion of the CASPA form are supported by the narrative letters submitted on behalf of the applicant.

\section{REFERENCES:}

1. Patterson, F, Knight, A, Dowell, J, Nicholson, S, Cousans, F, and Cleland, J. How effective are selection methods in medical education? A systematic review. Medical Education 2016; 50, pg. 36-60.

2. Marwan, Y, Waly, F, Algarni, N, Addar A, Saran N, Snell L. The role of letters of recommendation in the selection process of surgical residents in Canada: A national survey of program directors. Journal of Surgical Education 2017: 74, pg. 762-767.

3. Dutt K, Pfaff DL, Bernstein AF, Dillard JS, Block CJ. Gender differences in recommendation letters for postdoctoral fellowships in geoscience. Nature Geoscience 2016; 9: 805-808.

4. Akos P, Kretchmar J. (2016). Gender and ethnic bias in letters of recommendation: Considerations for school counselors. Professional School Counseling: 2016; 20: 102-113.

5. Messner AH, Shimahara, E. Letters of recommendation to an Otolaryngology/Head and Neck Surgery residency program: Their function and the role of gender. The Laryngoscope 2008; 118: 1335-1344.

6. Ceci SJ, Peters D. Letters of reference: A naturalistic study of the effects of confidentiality. American Psychologist 1984; 39: 29-31.

7. Alweis R, Collichio F, Milne CK, Dalal B, Williams, CM, Sulistio MS, Roth TK, Muchmore EA. Guidelines for a standardized fellowship letter of recommendation. The American Journal of Medicine 2017,130: 606-11 
8. Love JN, Ronan-Bentle SE, Lane DR, Hegarty CB. The standardized letter of evaluation for postgraduate training: A Concept whose time has come? Journal of the Association of American Medical Colleges 2016, 91: 1480-1482.

9. Kominsky AH, Bryson PC, Benninger MS, Tierney WS. Variability of ratings in the otolaryngology standardized letter of recommendation. Otolaryngology Head and Neck Surgery 2016; 154: 287-293. 